Catalysis B: Environmental

Elsevier Editorial System(tm) for Applied Manuscript Draft

Manuscript Number:

Title: 3D-Printed Fe-Doped Silicon Carbide Monolithic Catalysts for Wet Peroxide Oxidation Processes

Article Type: Research Paper

Keywords: 3D printing, monolith, silicon carbide, robocasting, catalytic wet peroxide oxidation

Corresponding Author: Dr. Asuncion Quintanilla, Dr

Corresponding Author's Institution: Universidad Autónoma de MAdrid

First Author: Asuncion Quintanilla, Dr

Order of Authors: Asuncion Quintanilla, Dr; Jose A Casas, Dr; Pilar

Miranzo, Dr.; Maria I Osendi, Dr.; Manuel Belmonte, Dr 


\title{
3D-Printed Fe-Doped Silicon Carbide Monolithic Catalysts for Wet Peroxide Oxidation
}

\section{Processes}

A. Quintanilla*\$, J. A. Casas ${ }^{\S}$, P. Miranzo ${ }^{\ddagger}$, M. I. Osendi ${ }^{\ddagger}$, M. Belmonte ${ }^{*}$

${ }^{\S}$ Sección de Ingeniería Química, Universidad Autonoma de Madrid, 28049 Madrid, Spain

${ }^{\ddagger}$ Institute of Ceramics and Glass (ICV-CSIC), 28049 Madrid, Spain

* Corresponding authors. Tel/Fax: +34 914973454/+34 914973516. E-mail address: asun.quintanilla@uam.es, mbelmonte@icv.csic.es

\begin{abstract}
The catalyst stability has become a key issue for wet peroxide oxidation (CWPO) processes. Herein, an alternative method for the manufacturing of iron (Fe) catalysts by using threedimensional (3D) printing techniques is proposed to enhance the Fe immobilization, where these metallic nanoparticles are part of a printable aqueous silicon carbide (SiC)-based ink. Cylindrical Fe/SiC monoliths (D 13 mm, H 4.5 mm, 74 squared cells $\cdot \mathrm{cm}^{-2}$ ) are manufactured by direct ink writing (Robocasting) and further treatment up to $1500^{\circ} \mathrm{C}$ into a spark plasma sintering (SPS) furnace to assure a certain mechanical integrity. It was found that the increasing SPS temperature progressively decreases the porosity -or increases the apparent density- of the printed struts, lowering the accessibility of reactants to the Fe sites but improving the catalyst mechanical strength and leaching resistance. $3 \mathrm{D} \mathrm{Fe} / \mathrm{SiC}$ monoliths treated at $1200{ }^{\circ} \mathrm{C}$ arise as robust catalysts for CWPO processes due to the combination of good catalytic activity, highly- efficient $\mathrm{H}_{2} \mathrm{O}_{2}$ decomposition, long-term stability and excellent mechanical strength. The simple potential kinetic model is proposed, capable of describing the phenol disappearance, TOC removal and $\mathrm{H}_{2} \mathrm{O}_{2}$ consumption. The results of this study point out a new approach for the conformation by
\end{abstract}


Robocasting of metal-based catalysts in suitable morphological 3D-structures for scaling-up reactions.

Keywords: 3D printing, monolith, silicon carbide, robocasting, catalytic wet peroxide oxidation.

\section{Introduction}

The treatment of the wastewater coming from industrial processes is increasingly becoming an environmental and health priority. Catalytic Wet Peroxide Oxidation (CWPO) is one of the most promising technologies to remove non-biodegradable contaminants in wastewater. CWPO operates under mild conditions (temperatures and pressures in the range of $25-100{ }^{\circ} \mathrm{C}$ and $0.1-0.5$ MPa, respectively) [1] and employs hydrogen peroxide $\left(\mathrm{H}_{2} \mathrm{O}_{2}\right)$ as oxidant, which is considered an environmentally friendly agent. This process requires a solid catalyst with redox properties to generate hydroxyl $(\mathrm{HO} \bullet)$ and hydroperoxy (HOO•) radicals from $\mathrm{H}_{2} \mathrm{O}_{2}$ decomposition. These radical species easily react with the pollutants, oxidizing them.

The catalyst par excellence is iron $(\mathrm{Fe})$ due to its low cost and high-organic oxidation activity. Fe is usually anchored to different materials as iron oxide in powder or granular form, viz. alumina [2], silica [3], titania [4], zeolites [5], mesoporous molecular sieves [6], pillared clays [7] and activated carbon [8]. However, the poor resistance offered by Fe containing materials to leaching under the acidic conditions of the CWPO process is limiting its industrial application. Therefore, different approaches are being explored, among others, the employ of alternative catalysts either metal-based ones, such as copper [9], manganese [10], cobalt [11], gold [12] or metal-free carbon catalysts [13]. When metal leaching is not significant or even null, as it is the case of carbonbased catalysts, the contribution of the homogeneous reaction is avoided and, thus, modest 
catalytic activities are achieved [14]. The high-cost gold nanoparticles are an exception but in spite of a high catalytic activity, they are susceptible to reversible poisoning by oxidation intermediates [15]. On the other hand, the industrial implementation of the CWPO catalysts that implies their conformation in suitable morphological characteristics with the appropriate mechanical strength remains scarcely explored.

The above highly demanding requirements could be accomplished by employing additive manufacturing techniques [16] to design with a precise control of the size and shape, rigid structures with embedded catalysts adapted to the requirements of the CWPO process. Herein, we propose the use of cost-effective direct ink writing techniques such as robocasting $[17,18]$ to produce three-dimensional (3D) architected ceramics by colloidal processing employing an aqueous-based ink containing the catalytic material. At present, scarce works can be found on 3D catalysts directly obtained by robocasting [19-21]. However, we expect upcoming interest in the application of this technique to the catalyst manufacturing because it can overcome the intricacies of the scale-up of heterogeneous catalyst (large sizes, scale-up formulation and structuring). The recent study by Tubio et al. [21], the only reported work up to now that focus on metal-based catalysts with a woodpile porous structure achieved by robocasting, provided promising results by demonstrating the good recyclability of these $3 \mathrm{D}$ printed $\mathrm{Cu} / \mathrm{Al}_{2} \mathrm{O}_{3}$ catalysts in Ullmann reactions without leaching contamination of the reaction products.

The mechanical integrity of the 3D printed structures that allows manipulating them when using as catalysts is also an important advantage. Although that integrity should increase with the density of the scaffold [22], at the same time, it could compromise their catalytic activity by decreasing the porosity and, hence, the number of available catalytic active sites. 
This work will accomplish the robocasting of 3D Fe/silicon carbide ( $\mathrm{SiC}$ ) catalysts by architecting colloidal suspensions of Fe-doped (0.52 wt.\%) SiC powders into porous monoliths. $\mathrm{SiC}$ is selected as the catalyst support due to its excellent corrosion resistance to most chemicals, in addition to other attractive properties like low density, good thermal stability and high strength $[23,24]$. The challenge in the fabrication of this $3 \mathrm{D}$ Fe incorporated monoliths for the CWPO process is to trade-off a good catalytic properties (activity and stability) -promoted by the embedded $\mathrm{Fe}$ active sites accessible in the $\mathrm{SiC}$ porous structure- and a certain mechanical strength. Both requirements could be met by tailoring the porosity of the solid structure through heat treatments of the $\mathrm{SiC}$ support at temperatures that only produce a partial sintering, presently from 1000 to $1500{ }^{\circ} \mathrm{C}$ in a spark plasma furnace. The catalytic activity and stability of $\mathrm{Fe} / \mathrm{SiC}$ monoliths thus obtained are studied in the CWPO of phenol, a common pollutant in wastewaters [25]. The results describing the effect of process variables including temperature, initial phenol, total organic carbon (TOC) and $\mathrm{H}_{2} \mathrm{O}_{2}$ concentrations are modelled according to some proposed reaction kinetics. The effect of mass transfer limitation on the CWPO of phenol is also reported. To the best of our knowledge, no reports can be found on 3D printed catalyst for CWPO reactions hitherto.

\section{Experimental}

\subsection{Monolith fabrication}

Nanosized $\beta$-SiC powders containing 0.52 wt. \% of Fe (Nanostructured \& Amorphous Materials Inc. -NanoAmor-, polytype $3 \mathrm{C}$ with mean $\mathrm{SiC}$ particle size of $45-55 \mathrm{~nm}$ ) were employed as starting material. The apparent viscosity $(\eta)$ and the storage $\left(G^{\prime}\right)$ and loss $\left(G^{\prime \prime}\right)$ moduli of the $\mathrm{Fe} / \mathrm{SiC}$ inks were determined with a rheometer (CVO $100 \mathrm{D}$, Bohlin Instruments) equipped with 
a cone-and-plate geometry (diameter: $40 \mathrm{~mm}$; cone angle: $4^{\circ}$ ). For $\eta$, the shear stress $(\tau)$ was recorded as shear rate $(\dot{\gamma})$ was increased from $0.0878-200 \mathrm{~s}^{-1}$. For $\mathrm{G}^{\prime}$ and $\mathrm{G}^{\prime \prime}$ data, oscillation measurements were performed at a frequency of $1 \mathrm{~Hz}$ and ascending stress sweep from 0.5 to $1000 \mathrm{~Pa}$. Printable Fe/SiC inks were developed sequentially adding to deionized water the following materials: $55.7 \mathrm{wt} . \%$ of $\mathrm{Fe} / \mathrm{SiC}, 3.7 \mathrm{wt} . \%$ of high molecular weight polyethylenimine (H-PEI, PEI 25000, Sigma Aldrich; < 1 wt.\% of water content), 3.8 wt.\% of low molecular weight polyethylenimine (L-PEI, PEI 2000, Sigma Aldrich; 50 wt.\% of water content), 7.0 wt.\% of hydroxypropyl methylcellulose (MC, Methocel F4M, Dow Chemical Co.; 95 wt.\% of water content). After each addition, the ink was homogenized by planetary centrifugal mixing (ARE250, Thinky Company) at 2000 r.p.m. for 30-60 s. 3D cylindrical Fe/SiC periodic lattices were computer designed (RoboCAD 4.0, 3-D Inks LLC) and reproduced at room temperature onto an alumina substrate with a custom three-axis robocasting system (A-3200, 3-D Inks LLC) using tips with inner diameter of $330 \mu \mathrm{m}$. The ink extrusion speed was automatically controlled to keep a constant volumetric flow rate of $0.25 \pi \mathrm{D}^{2} v$, where $\mathrm{D}$ is the inner diameter of the nozzle and $v$ is the $\mathrm{X}-\mathrm{Y}$ table velocity set at $25 \mathrm{~mm} \cdot \mathrm{s}^{-1}$. The as-printed scaffolds were heat treated at 600 ${ }^{\circ} \mathrm{C}$ in air for $2 \mathrm{~h}$ to completely burn-out the organics employed for the ink formulation, according to the thermogravimetric analysis (Figure S1, Supporting information), and were employed as reference catalyst (labelled as REFERENCE). Some of these scaffolds were further pressureless sintered into a spark plasma sintering furnace (SPS, SPS-510CE; Fuji Electronic Industrial Co., Ltd) to induce differences of density, i.e. porosity, in the structures, looking for a convenient balance between the CWPO performance and the adequate strength. The heat treatments were carried out in an argon atmosphere $(\sim 6 \mathrm{kPa})$ at temperatures ranging from 1000 to $1500{ }^{\circ} \mathrm{C}$, 
holding for $5 \mathrm{~min}$ at the set temperature. The resulting monoliths are labelled as SPS-1000, SPS1200 and SPS-1500 referring to the corresponding treatment temperatures.

\subsection{Structure characterization}

Total porosity $\left(\varepsilon_{t}\right)$ was determined as the sum of the macro-porosity due to the patterned design and the micro-porosity of the ceramic struts, estimated by the Archimedes' method using distilled water as the immersion medium. The apparent density $\left(\rho_{p}\right)$ of the monoliths correspond to the mass of $\mathrm{Fe} / \mathrm{SiC}$ catalyst per volume occupied by the solid struts. Fracture surfaces of struts were observed with a field emission scanning electron microscope (FESEM; Hitachi S-4700). Median grain diameter $\left(\mathrm{d}_{50}\right)$ of the $\mathrm{SiC}$ support as a function of the SPS treatment was estimated by imaging analysis methods on FESEM images considering at least 700 features. Specific surface area was obtained in a Micromeritics Tristar 3000 apparatus. The overall Fe content in the monoliths was determined by total reflection X-ray fluorescence (TXRF EXTRA II, Rich \& Seifert). Transmission electron microscopy (TEM) images were taken on mortar crushed specimens with a JOEL JEM 2100 at an accelerating voltage of $200 \mathrm{kV}$. X-ray photoelectron

spectroscopy (XPS) analysis was carried out using a Physical Electronics (mod. ESCA 5701) equipped with a monochromatic Mg Ka X-ray excitation source. The binding energies in the Fe $2 p$ spectra were calibrated by setting $\mathrm{C} 1 \mathrm{~s}$ at $284.6 \mathrm{eV}$.

\subsection{Mechanical characterization}

3D Fe/SiC scaffolds were compression tested using a universal testing machine (ZwickiLine Z5.0 TS, Zwick-Roell) and a displacement rate of $0.5 \mathrm{~mm} \cdot \mathrm{min}^{-1}$ until crushing. The robocast specimens were previously ground at the top/bottom surfaces to assure a homogenous distribution of the load on the whole 3D structure. Stress and strain values were determined from 
the load and displacement data, and the compressive strength was calculated from the load at failure and the nominal contact surface area.

\subsection{CWPO experiments}

The catalytic activity of the different Fe/SiC monoliths, viz. REFERENCE, SPS-1000, SPS-1200 and SPS-1500, for the CWPO of phenol was studied in a tubular double jacket glass reactor $\left(\mathrm{d}_{\mathrm{i}}=15 \mathrm{~mm}\right)$ operated in up-flow mode and loaded with three monolithic pieces (total weight, $\mathrm{W}$ $=0.93 \mathrm{~g}$ ). The runs were conducted at $[\text { Phenol }]_{0}=1 \mathrm{~g} \cdot \mathrm{L}^{-1},\left[\mathrm{H}_{2} \mathrm{O}_{2}\right]_{0}=5 \mathrm{~g} \cdot \mathrm{L}^{-1}$, natural $\mathrm{pH}, \mathrm{T}=75$ ${ }^{\circ} \mathrm{C}$, residence time $\left(\mathrm{t}_{\mathrm{r}}\right)=0-10 \mathrm{~min}$ and space time $(\tau)=0-130 \mathrm{~g} \mathrm{CAT} \cdot \mathrm{h} \cdot \mathrm{L}^{-1}$. Control experiments in absence of catalyst, with the original $\beta$-SiC commercial nanoparticles and alternatively with $\beta$ $\mathrm{SiC}$ nanoparticles with just traces of $\mathrm{Fe}(0.05 \mathrm{wt} . \%)$ were performed at the same operating conditions. The latter nanoparticles resulted from the washing of the as-received $\beta-\mathrm{SiC}$ commercial nanoparticles, typically $2.5 \mathrm{~g}$ of $\mathrm{SiC}$ in $250 \mathrm{~mL}$ of $\mathrm{HCl}(37 \%)$ for $24 \mathrm{~h}$ under vigorous stirring at room temperature.

The long-term stability of the SPS-1200 monoliths was tested in a reactor loaded with nine cylindrical pieces ( $\mathrm{W}=2.83 \mathrm{~g}$ ) at the above selected conditions for CWPO performance and at two flow rates, 0.5 and $0.125 \mathrm{~mL} \cdot \mathrm{min}^{-1}$, corresponding with $\tau=94$ and $378 \mathrm{~g}_{\mathrm{CAT}} \cdot \mathrm{h} \cdot \mathrm{L}^{-1}$ or $\mathrm{t}_{\mathrm{r}}=6$ and $24 \mathrm{~min}$, respectively. Further kinetic experiments were carried out over a wide range of operating conditions: $[\mathrm{Phenol}]_{0}=0.5-5 \mathrm{~g} \cdot \mathrm{L}^{-1},\left[\mathrm{H}_{2} \mathrm{O}_{2}\right]_{0}=2.5-6.5 \mathrm{~g} \cdot \mathrm{L}^{-1}, \mathrm{~T}=65-85^{\circ} \mathrm{C}$ and $\tau=0$ $378 \mathrm{~g}_{\mathrm{CAT}} \cdot \mathrm{h} \cdot \mathrm{L}^{-1}$.

\subsection{Analytical methods}


Liquid samples from the reactor were analyzed by different procedures. Phenol and aromatic byproducts were determined by high performance liquid chromatography (HPLC, Varian, Mod. ProStar, PDA detector with a $5 \mu \mathrm{m}$ FORTIS C18 column 150 x $4.6 \mathrm{~mm}$ ); whereas TOC was estimated using a specific analyzer (Shimadzu TOC VSCH). $\mathrm{H}_{2} \mathrm{O}_{2}$ concentration was determined by employing the $\mathrm{TiOSO}_{4}$ method. The content of $\mathrm{Fe}$ in solution was measured by colorimetric test with an ORBECO -Hellige MC500 Colorimeter and, in some samples, also confirmed by TXRF.

\section{Results and discussion}

\subsection{Fabrication and characterization of Fe/SiC monoliths}

The manufacturing process of the $\mathrm{Fe} / \mathrm{SiC}$ scaffolds first required the development of a printable ink, which must exhibit an adequate pseudoplastic behaviour. To achieve this goal, different organic additives were sequentially added to an $\mathrm{Fe} / \mathrm{SiC}$ containing aqueous ink, starting with $\mathrm{H}$ PEI and L-PEI that were employed as dispersant agents to improve the solids content, followed by the addition of MC as viscosifying agent. The ink composition was formed by $38.3 \mathrm{wt} . \%$ of deionized water, 55.7 wt.\% of $\mathrm{Fe} / \mathrm{SiC}$, and $6.0 \mathrm{wt} . \%$ of organics $(62.5,28.2$, and 9.3 in vol.\%, respectively). The resulting ink presented a shear thinning behaviour, as it was confirmed by the decrease of several orders of magnitude of the apparent viscosity as the shear rate augmented from $10^{-1}$ to $10^{2} \mathrm{~s}^{-1}$ (Figure 1a). This response allowed printing low viscous $(\eta=6-10 \mathrm{~Pa} \cdot \mathrm{s})$ $\mathrm{Fe} / \mathrm{SiC}$ ceramic filaments through the fine tip ( $330 \mu \mathrm{m}$ inner diameter) in the shear rate region of $30-70 \mathrm{~s}^{-1}$, and retaining their shape once printed because the abrupt increase in viscosity $\left(>10^{4}\right.$ Pa.s) after setting. In addition, the ink exhibited (Figure $1 \mathrm{~b})$ both high storage modulus ( $\mathrm{G}^{\prime} \sim 5 \mathrm{x}$ $10^{4} \mathrm{~Pa}$ ) and yield stress $\left(\tau_{\mathrm{y}} \sim 10^{3} \mathrm{~Pa}\right)$-defined by the point where G' (loss modulus) equals to 
G'- which facilitated retaining the filamentary shape and avoided the collapse of the built 3D structures. Cylindrical $\mathrm{Fe} / \mathrm{SiC}$ periodic scaffolds of $\sim 13 \mathrm{~mm}$ of diameter and $\sim 4.5 \mathrm{~mm}$ of height (20 filament layers) with a spanned distance between the filaments in the linear array of $\sim 1.3$ $\mathrm{mm}$ were computer-aided designed (Figure 1c). The monoliths contain 74 square cells per $\mathrm{cm}^{2}$.

Table 1 collects the apparent density and the total porosity of the REFERENCE and the scaffolds sintered at different temperatures. As sintering additives were not added to the $\mathrm{SiC}$ powders, densification was mostly inhibited. The $\rho_{\mathrm{p}}$ values of the monoliths increasing from $1.13 \mathrm{~g} \cdot \mathrm{cm}^{-3}$ (REFERENCE) up to $1.72 \mathrm{~g} \cdot \mathrm{cm}^{-3}$ (SPS-1500), which constitutes an increment in the density of $50 \%$ with the $1500{ }^{\circ} \mathrm{C}$ SPS treatment but it is far from the theoretical density of $\mathrm{SiC}=3.22$ $\mathrm{g} \cdot \mathrm{cm}^{-3}$. Conversely, as expected, $\varepsilon_{\mathrm{t}}$, taken as the sum of the macro-porosity due to the patterned design and the micro-porosity of the ceramic struts, decreased from 70.0\% (REFERENCE) to $65.6 \%$ (SPS-1500), diminishing the surface area $\left(\mathrm{S}_{\mathrm{BET}}\right)$ as well (Table 1). The dimensions of the cylindrical Fe/SiC monoliths are: $\mathrm{D} \sim 13 \mathrm{~mm}, \mathrm{H} \sim 4.5 \mathrm{~mm}, \mathrm{D}_{\text {open }} \sim 0.9 \mathrm{~mm}$ and $\delta_{\mathrm{w}}=0.26 \mathrm{~cm}$.

As an example, Figure 2a shows a representative image of the fracture surface of one of the monoliths, in particular, the SPS-1200 one, where the retention of the 3D architecture is clearly visible. The analysis of the microstructure of the ceramic struts (Figure 2b) revealed that the mean particle size of $\mathrm{SiC}$ was in the range of $39-46 \mathrm{~nm}$ for all monoliths independently of the SPS treatment, value that was also similar to the particle size of the original powders $(45 \mathrm{~nm})$.

Regarding the active catalytic phase, the Fe content remained invariable for all the monoliths, i.e. $0.52 \pm 0.03 \mathrm{wt} . \%$, with a diameter of $12.7 \pm 4.5 \mathrm{~nm}$ for the isolated spherical Fe nanoparticles as determined by the TEM images (Figure 2c). Besides, the surface content of Fe and its oxidation state in the struts for the different SPSed monoliths was determined by analysing of the XPS 
signal in the $\mathrm{Fe} 2 \mathrm{p}$ region. The spectrum of the REFERENCE sample is provided in Figure $2 \mathrm{~d}$ as representative example. Two main peaks located at 710.6 and $723.0 \mathrm{eV}$ were clearly observed and ascribed to $\mathrm{Fe} 2 \mathrm{p}_{3 / 2}$ and $2 \mathrm{p}_{1 / 2}$ cationic species, respectively [26]. The two satellite peaks located at energy values c.a. 3.5 and $7.6 \mathrm{eV}$ higher than the corresponding main peaks (Figure 2d) corresponded to $\mathrm{Fe}^{2+}$ and $\mathrm{Fe}^{3+}$, respectively. The same cationic $\mathrm{Fe}$ species were detected for the SPSed monoliths (Figure S2 of the Supporting Information shows the spectrum recorded for SPS-1500). Both ionic states of $\mathrm{Fe}$ are catalytically active in the decomposition of $\mathrm{H}_{2} \mathrm{O}_{2}$ [27]. The overall $\mathrm{Fe}$ content on the outermost surface of the $\mathrm{SiC}$ scaffold calculated from the deconvolution of the main XPS peaks is collected in Table 1. While for the REFERENCE material that content was $0.33 \mathrm{wt} . \%$, it considerably decreased (30-40\% reduction) for the SPSed monoliths.

\subsection{CWPO performance}

First, it was verified that liquid-phase reaction (in absence of catalyst) was not competitive with the catalysts. Furthermore, the $\mathrm{Fe} / \mathrm{SiC}$ raw powders exhibited a high catalytic activity (likely caused by the contribution of the significant leached Fe content), with a conversion of phenol and TOC of 100 and $60 \%$, respectively, at 1 min of residence time. The powders became inactive once washed with a strong acid (Fe content within the $\mathrm{SiC}$ powders dropped to 0.05 wt.\%), which evidenced that the catalytic activity is clearly associated to Fe.

When the different $\mathrm{Fe} / \mathrm{SiC}$ monoliths were used in the CWPO reaction, the initial exposure to the reacting stream triggered the leaching of the most liable Fe during approximately $30 \mathrm{~h}$ on stream, reaching, afterwards, a stable stage where the Fe content in the effluents became insignificant. The Fe leachability decreased with the SPS temperature (see values of $\mathrm{Fe}_{\text {leached }}$ in Table 1), from 
18.5 (REFERENCE) to $5.2 \mathrm{wt} \%$ (SPS-1500). These results reflect a lower availability of the Fe active sites for the catalytic reaction as the temperature increased, also confirmed by the XPS spectra (FexPS data in Table 1).

The results obtained in the CWPO of phenol for all monoliths are shown in Figure 3. Fe leaching was negligible in all the experiments because profiles were obtained after $30 \mathrm{~h}$ on-stream catalysts. As it can be seen, distinct conversion (X) profiles of phenol (Figure 3a) and TOC (Figure $3 b) v s$. space time $(\tau)$ are obtained. Figure $3 \mathrm{c}$ illustrates the effect of the heat treatment on the apparent kinetic constants $\left(k_{\text {app }}\right)$ calculated assuming a pseudo-first order kinetic reaction. $k_{\text {app }}$ progressively diminished with the SPS temperature up to $1200{ }^{\circ} \mathrm{C}$ and, then, more abruptly for the $1500{ }^{\circ} \mathrm{C}$ treatment, observing for this latter 3D catalyst a reduction of activity with respect to the REFERENCE monolith of 50 and $70 \%$ for phenol disappearance and TOC removal, respectively. Considering that the $k_{a p p}$ values do not correlate with the remaining $\mathrm{Fe}$ content (lower in the SPS-1000 than SPS-1500, as indicated in Figure 3c), it seems reasonable to attribute the differences in the catalytic behaviour of the monoliths to a lower accessibility of the Fe active sites to reactants, which is caused by the decrease in $\varepsilon_{t}$ or the increase in $\rho_{p}$ (Table 1). $\mathrm{Fe} / \mathrm{SiC}$ monoliths also worked as efficient catalysts in the decomposition of $\mathrm{H}_{2} \mathrm{O}_{2}$ into radical species, as it can be seen in Figure $3 \mathrm{~d}$ where TOC vs. $\mathrm{H}_{2} \mathrm{O}_{2}$ conversions are depicted. The consumption of $\mathrm{H}_{2} \mathrm{O}_{2}$ is equivalent to TOC abatement, which indicates that the radical species formed, $\mathrm{HO} \bullet$ and $\mathrm{HOO} \bullet$, reacted with the organic compounds (phenol and by-product species) instead of being consumed in spurious parasite reactions. The selected SPS temperature studied have no influence on the catalyst $\mathrm{H}_{2} \mathrm{O}_{2}$-efficiency, at least within the levels of TOC removal here achieved. Due to the poor activity achieved by the SPS-1500 monoliths, they were not considered for further experiments. 
In addition to a good catalytic behaviour, the monoliths should also exhibit an adequate mechanical integrity for their manipulation under service conditions. Then, compression tests were performed for REFERENCE, SPS-1000 and SPS-1200 monoliths and representative examples of their stress-strain curves are collected in Figure 4a. All the scaffolds initially presented a linear elastic region that extended until reaching the maximum stress value (compressive strength, $\sigma$ ). Within this elastic region, the beams in $\mathrm{Fe} / \mathrm{SiC}$ cells progressively bent and fractured until the scaffold collapsed. As the $\rho_{\mathrm{p}}$ of the scaffolds augmented, larger crushing strengths, $\sigma$, were attained (Figure $4 \mathrm{~b}$ ). In fact, $\sigma$ increases by $120 \%$ when comparing the REFERENCE monoliths $\left(\rho_{\mathrm{p}}=1.13 \mathrm{~g} \cdot \mathrm{cm}^{-3}, \sigma=1.6 \mathrm{MPa}\right)$ to the SPS-1200 ones $\left(\rho_{\mathrm{p}}=1.51\right.$ $\mathrm{g} \cdot \mathrm{cm}^{-3}, \sigma=3.5 \mathrm{MPa}$ ), following parabolic trend with density. This increment in $\sigma$ was also accompanied by higher strains $(\sim 30 \%)$ of the structure at fracture, The stress-strain curves showed a slow drop of the stress after the maximum $\sigma$ value was attained (Figure 4a), indicating of certain load bearing capability of the structure instead of a catastrophic failure. This behaviour is linked to the progressive collapse of the $\mathrm{Fe} / \mathrm{SiC}$ cells that produced the gradual fracture of the monoliths

According to the above results, the SPS-1200 monoliths arise as the best option to balance both reasonable mechanical strength and good catalytic activity in CWPO reactions. Next, a deep insight into the CWPO over these selected monoliths will be carried out by testing the operational stability in long-term use and obtaining the kinetic model for the CWPO of phenol that can be very useful for optimizing process conditions.

\subsection{Catalyst stability}


The key point in the application of novel heterogeneous catalysts in CWPO is the stability with time-on-stream, which could be questionable due to the amount of active Fe initially lost by leaching (Table 1). A reactor loaded with nine cylindrical SPS-1200 monoliths ( $\mathrm{W}=2.83 \mathrm{~g}$ ) was used to perform the long-term operation at large space-times, $\tau=94.4$ and $378 \mathrm{~g}_{\mathrm{cat}} \cdot \mathrm{h} \cdot \mathrm{L}^{-1}$. The constant values of phenol and TOC conversions with time on stream (Figure 5) evidenced that the SPS-1200 catalyst exhibits an excellent stability with no apparent deactivation for $350 \mathrm{~h}$ on stream once overpassed the initial period of $20 \mathrm{~h}$. In addition, Fe leached out during this period at $378 \mathrm{~g}_{\mathrm{cat}} \cdot \mathrm{h} \cdot \mathrm{L}^{-1}$ (or $6 \mathrm{~min}$ of residence time) was $3.5 \%$ of the initial Fe weight.

\subsection{Mass transfer analysis and kinetic modelling}

The existence of external mass transfer limitation must be previously verified by experimentation. The liquid solid mass transfer coefficients of reactants cannot be estimated by the existing correlations for monolith reactors [28] because the flow pattern inside the monolith channel during the CWPO reaction is unpredictable. Besides, the flow is changeable along the length of the channel due to the progressive mineralization of phenol and oxidized intermediates that results in the generation of volatile compounds such as $\mathrm{CO}_{2}$ and $\mathrm{CO}$ [29]. Thus, the external mass transfer limitation was experimentally verified by studying the effect of the liquid flow rate $\left(\mathrm{Q}_{\mathrm{L}}=0.125-2 \mathrm{~mL} \cdot \mathrm{min}^{-1}\right)$ on phenol and $\mathrm{H}_{2} \mathrm{O}_{2}$ conversions (Figures $6 \mathrm{a}$ and $\mathrm{b}$, respectively) within a similar range of weight hour space velocity (WHSV=reactant mass flow/mass of catalyst), calculated as $\mathrm{Q}_{\mathrm{L}} \cdot\left[\mathrm{Phenol} \text { or } \mathrm{H}_{2} \mathrm{O}_{2}\right]_{0} \cdot \mathrm{W}^{-1}$, in $\left.\mathrm{g}_{\text {phenol or } \mathrm{H} 2 \mathrm{O} 2} \cdot \mathrm{g}_{\mathrm{cat}}{ }^{-1} \cdot \mathrm{h}^{-1}\right)$. The experiments were performed in reactors of two different lengths loaded with three and nine monolith structures, the amount of catalyst being 0.95 and $2.83 \mathrm{~g}$, respectively. The liquid flow rate was proportionally changed to the reactor length to keep the WHSV constant. Figures $6 \mathrm{a}, \mathrm{b}$ show that phenol and $\mathrm{H}_{2} \mathrm{O}_{2}$ conversions data $v s$. WHSV in both reactors show the same profile at similar conditions of 
temperature and reactant concentrations, indicating that external mass transfer limitations can be neglected.

Within the above liquid flow rate range, the oxidation experiments were then performed at different operating conditions for initial phenol concentrations $\left(500-1500 \mathrm{mg} \cdot \mathrm{L}^{-1}\right), \mathrm{H}_{2} \mathrm{O}_{2}$ dosages (100-130\% stoich. dosage) and temperatures $\left(65-85^{\circ} \mathrm{C}\right)$ in the reactor loaded with $2.83 \mathrm{~g}$ of SPS1200 monoliths. The effect of each variable on phenol (Figure 7), TOC (Figure 8) and $\mathrm{H}_{2} \mathrm{O}_{2}$ (Figure 9) concentrations at the reactor outlet was studied as a function of $\tau$ by keeping all other variables constant. Interestingly, at the most severe conditions, $85{ }^{\circ} \mathrm{C}$ and $378 \mathrm{~g}_{\mathrm{CAT}} \cdot \mathrm{h} \cdot \mathrm{L}^{-1}$ (equivalent to a $\mathrm{t}_{\mathrm{r}}=36 \mathrm{~min}$ ), complete phenol disappearance, $70 \%$ TOC removal and $72 \% \mathrm{H}_{2} \mathrm{O}_{2}$ consumption were achieved using the typical inlet effluent in CWPO studies $\left(1 \mathrm{~g} \cdot \mathrm{L}^{-1}\right.$ of phenol solution and the stoichiometric dosage of $\mathrm{H}_{2} \mathrm{O}_{2}$ ).

Different models were proposed to fit by nonlinear regression to the experimental data of Figures 7, 8 and 9. The numerical integration of the rate equations, assuming isothermal plug-flow inside the channel, was solved at each temperature with the Microsoft Excel Solver (Microsoft Office 2010, MicrosoftCorp.) based on the Generalized Reduced Gradient (GRG) algorithm for least squares minimization. The pre-exponential factors and activation energies were estimated by the Arrhenius equation. The following power-law kinetic expressions are the best fitting to the experimental data:

$$
\begin{gathered}
\left(-r_{\text {PHENOL }}\right)\left(\frac{m g \text { PHENOL }}{g_{\text {cat }} \cdot h}\right)=1.05 \cdot 10^{4} \cdot e^{-\frac{4885 \pm 673}{T}} \cdot C_{\text {fenol }} \\
\left(-r_{\text {TOC }}\right)\left(\frac{m g \text { CARBON }}{g_{\text {cat }} \cdot h}\right)=5.32 \cdot 10^{6} \cdot e^{-\frac{9724 \pm 62}{T}} \cdot C_{\text {TOC }}^{2} \\
\left(-r_{H 2 O 2}\right)\left(\frac{m g H 2 O 2}{g_{\text {cat }} \cdot h}\right)=1.83 \cdot 10^{5} \cdot e^{-\frac{6263 \pm 2016}{T}} \cdot C_{H 2 O 2}
\end{gathered}
$$


The predicted concentration vs. $\tau$ profiles calculated from the discriminated model, Eqs. [1-3], have been included in Figures 7-9. The parity plots shown in Figure S3 of the Supporting Information also illustrate the validation of this model. Power-law kinetics have been commonly reported in CWPO processes over different catalysts [15, 30-32].

Herein, phenol disappearance and $\mathrm{H}_{2} \mathrm{O}_{2}$ consumption rates follow first-order kinetics, while a second order is obtained for TOC, species that lump all the organic compounds present in the liquid phase. Note from Figure $7 \mathrm{~b}$ and Figure $8 \mathrm{~b}$ that phenol disappearance and TOC removal rates do not depend on $\mathrm{H}_{2} \mathrm{O}_{2}$ concentration. It is usually considered that concentration of the radical species $\mathrm{HO}$ and $\mathrm{HOO}$ is constant and, therefore, they can be included in the kinetic constant.

To determine whether the rate reactions are limited by the internal diffusion of the reactants along the wall thickness of the channels $\left(\delta_{\mathrm{w}}=0.026 \mathrm{~cm}\right)$, the internal effectiveness factor in the phenol disappearance and $\mathrm{H}_{2} \mathrm{O}_{2}$ decomposition reactions ( $\eta_{\text {phenol }}$ and $\eta_{\mathrm{H} 2 \mathrm{O} 2}$, respectively) were estimated at three reaction temperatures, 65,75 and $85^{\circ} \mathrm{C}$, as a function of the Thiele Modulus $(\phi)$ :

$$
\phi=L \cdot \sqrt{\frac{k_{v}}{D_{e f f}}}
$$

in which the characteristic length, $\mathrm{L}$, is equal to half of the $\delta_{\mathrm{w}}(\mathrm{in} \mathrm{cm}), \mathrm{k}_{\mathrm{v}}$ is the observed kinetic constant $\left(\mathrm{s}^{-1}\right)$ of Eqs. [1] and [3] and $\mathrm{D}_{\text {eff }}$ is effective diffusivity $\left(\mathrm{cm}^{2} \cdot \mathrm{s}^{-1}\right)$ calculated from the molecular diffusion of each of reactant in water, with a tortuosity factor assumed to be 2 and a particle porosity equal to 0.13 . The molecular diffusion of phenol and $\mathrm{H}_{2} \mathrm{O}_{2}$ in water was 
estimated using the Wilke-Chang correlation [33]. The values of molecular diffusion and effective diffusivity for both the phenol as well as the $\mathrm{H}_{2} \mathrm{O}_{2}$ at the different temperatures are given in Table S1 of the Supporting Information.

The internal effectiveness factor values for phenol and $\mathrm{H}_{2} \mathrm{O}_{2}$ as a function of the wall thickness are shown in Figures 6c and d, respectively. Applying the Wheeler-Weisz $(\Phi)$ criteria $\left(\Phi=\eta \cdot \phi^{2}<\right.$ 0.15) to evaluate the absence of the internal diffusion limitation, it can be seen that the wall diffusion limitation of $\mathrm{H}_{2} \mathrm{O}_{2}$ is neglected. Meanwhile, phenol disappearance rate is somehow diffusion-limited at temperatures from $75^{\circ} \mathrm{C}$. $\eta_{\text {phenol }}$ values of 0.94 and 0.92 should be considered for the estimation of the intrinsic kinetic constants at 75 and $85^{\circ} \mathrm{C}$, respectively (Figure $6 \mathrm{c}$ ).

\section{Conclusions}

The feasibility of the robocasting method for fabricating robust 3D Fe/SiC monolithic catalysts for CWPO processes using pseudoplastic Fe-doped SiC inks is demonstrated. This cost-effective method fully integrates the Fe catalyst into the ceramic scaffold and by further heat treatments, porosity (or apparent density) of the 3D structures can be tuned, thus modifying the access of the reactants to the Fe sites. The decrease of the porosity with temperature produces a detrimental effect in the catalytic activity but a noticeable resistant to Fe leaching, hence, the intermediate temperature treatment was the most effective.

Accordingly, $\mathrm{Fe} / \mathrm{SiC}$ monoliths treated at $1200{ }^{\circ} \mathrm{C}$ are promising catalysts for the treatment of wastewater by CWPO because they combine a high catalytic activity and efficiency in the $\mathrm{H}_{2} \mathrm{O}_{2}$ decomposition, good long-term stability (upon $350 \mathrm{~h}$ on stream) and excellent mechanical strength (3.5 MPa). The kinetic model adequately describes the target pollutant degradation (phenol), TOC removal and $\mathrm{H}_{2} \mathrm{O}_{2}$ consumption by a set of potential equations with different 
reaction orders (first order for phenol and $\mathrm{H}_{2} \mathrm{O}_{2}$, and second for TOC). Some phenol internal diffusion limitation $\left(\eta_{\text {phenol }}=0.94\right)$ needs to be considered from a reaction temperature of $75^{\circ} \mathrm{C}$.

The results of this study open new perspectives in the reactor engineering solution for catalytic wastewater treatments through the design and printing of monolithic structured reactors for CWPO processes. Robocasting is presented as one-step process for the development of metalbased catalysts in suitable morphological structures for scaling-up reactions.

\section{Acknowledgments}

This work was supported by the following projects: MAT2015-67437-R (MINECO, FEDER, UE) and CTM2016-76454-R (MINECO). The authors thank Dr. Daniel Gamarra for their help in the characterization studies by XPS.

\section{References}

[1] G. Pliego, J. A. Zazo, P. Garcia-Muñoz, J.A. Casas, J. J. Rodriguez. Intensification of the Fenton Process by Increasing the Temperature, Crit. Rev. Env. Sci. Technol. 45 (2015) 26112692.

[2] N. Al Hayek, J. P. Eymery, M. Doré, Catalytic oxidation of phenols with hydrogen peroxide. Structural study by Mossbauer spectroscopy of the catalysts $\mathrm{Fe} / \mathrm{Al}_{2} \mathrm{O}_{3}$ and $\mathrm{FeCu} / \mathrm{Al}_{2} \mathrm{O}_{3}$, Water Res. 19 (1985) 657-66. 
[3] J. A. Botas, J. A. Melero, F. Martinez, M. I. Pariente, Assessment of $\mathrm{Fe}_{2} \mathrm{O}_{3} / \mathrm{SiO}_{2}$ catalysts for the continuous treatment of phenol aqueous solutions in a fixed bed reactor, Catal. Today 149 (2010) 334-340.

[4] M. Ferentz, M. V. Landau, R. Vidruk, M. Herskowitz, M. Fixed-bed catalytic wet peroxide oxidation of phenol with titania and Au/titania catalysts in dark, Catal. Today 241 (2015) 63-72.

[5] K. Fajerwerg, J. Foussard, A. Perrard, H. Debellefontaine, Wet oxidation of phenol by hydrogen peroxide using heterogeneous catalysis Fe-ZSM-5: a promising catalyst, Water Sci. Technol. 35 (1997) 103-110.

[6] G. Calleja, J. A. Melero, F. Martínez, R. Molina, Activity and resistance of iron-containing amorphous, zeolitic and mesostructured materials for wet peroxide oxidation of phenol, Water Res. 39 (2005) 1741-1750.

[7] J. Barrault, M. Abdellaoui, C. Bouchoule, A. K. Majesté, J. M. Tatibouët, A. Louloudi, N. Papayannakos, N. H. Gangas, Catalytic wet peroxide oxidation over mixed (Al-Fe) pillared clays, App. Catal. B: Environ. 27 (2000) L225-L230.

[8] J.A. Zazo, J. A. Casas, A. F. Mohedano, J.J. Rodriguez, Catalytic wet peroxide oxidation of phenol with a Fe/active carbon catalyst, App.Catal. B: Environ. 65 (2006) 261-268.

[9] R. M. Liou, S. H. Chen, $\mathrm{CuO}$ impregnated activated carbon for catalytic wet peroxide oxidation of phenol, J. Hazard. Mater. 172 (2009) 498-506.

[10] N. Sui, Y. Duan, X. Jiao, D. Chen, Large-scale preparation and catalytic properties of onedimensional $\alpha / \beta-\mathrm{MnO} 2$ nanostructures, J. Phys. Chem. C, 113 (2009) 8560-8565. 
[11] F. Duarte, F. Maldonado-Hódar, A. Pérez-Cadenas, L. M. Madeira, Fenton-like degradation of azo-dye Orange II catalyzed by transition metals on carbon aerogels, App. Catal. B: Environ. 85 (2009) 139-147.

[12] Y. Han, N. Phonthammachai, K. Ramesh, Z. Zhong, T. White, Removing organic compounds from aqueous medium via wet peroxidation by gold catalysts, Environ. Sci. Technol. $42(2008)$ 908-912.

[13] S. Navalon, A. Dhakshinamoorthy, M. Alvaro, H. Garcia, Heterogeneous Fenton catalysts based on activated carbon and related materials, ChemSusChem. 4 (2011) 1712-1730.

[14] C. M. Dominguez, P. Ocón, A. Quintanilla, J. A. Casas, J.J. Rodriguez, Graphite and carbon black materials as catalysts for wet peroxide oxidation, App. Catal. B: Environ, 144 (2014) 599606.

[15] C. M. Dominguez, A. Quintanilla, J.A. Casas, J.J. Rodriguez, Kinetics of wet peroxide oxidation of phenol with a gold/activated carbon catalyst, Chem. Eng. J. 253 (2014) 486-492.

[16] X. Zhou, C.-J. Liu, Three- Dimensional Printing for Catalytic Applications: Current Status and Perspectives, Adv. Func. Mater. 27 (2017) 1701134.

[17] R. D. Farahani, M. Dubé, D. Therriault, Three-dimensional printing of multifunctional nanocomposites: manufacturing techniques and applications, Adv. Mater. 28 (2016) 5794-5821.

[18] J. E. Smay, G. M. Gratson, R. F. Shepherd, J. Cesarano III, J. A. Lewis, Directed colloidal assembly of 3D periodic structures, Adv. Mater. 14 (2002) 1279-1283.

[19] J. N. Stuecker, J. E. Miller, R. E. Ferrizz, J. E. Mudd, J. Cesarano III, Advanced support structures for enhanced catalytic activity, Ind. Eng. Chem. Res. 43 (2004) 51-55. 
[20] J. Azuaje, C. R. Tubío, L. Escalante, M. Gómez, F. Guitián, A. Coelho, O. Caamaño, A. Gil, E. Sotelo, Appl. Catal. A-General 530 (2017) 203-210.

[21] C.R. Tubío, J. Azuaje, L. Escalante, A. Coelho, F. Guitián, E. Sotelo, A. Gil, 3D printing of a heterogeneous copper-based catalyst, J. Catal. 334 (2016) 110-115.

[22] J. H. Eom, Y. W. Kim, S. J. Raju, Processing and properties of macroporous silicon carbide ceramics: a review, Asian Ceram. Soc. 1 (2013) 220-242.

[23] G. Roewer, U. Herzog, K. Trommer, E. Müller, S. Frühauf, Silicon-carbide- a survey of synthetic approaches, properties and applications, Struct. Bond. 101 (2002) 59-135.

[24] M. J. Ledoux, C. Pham-Huu, Silicon carbide: a novel catalyst support for heterogeneous catalysis, CATTECH 5 (2001) 226-246.

[25] E. V. Rokhina, J. Virkutyte, Environmental application of catalytic processes: heterogeneous liquid phase oxidation of phenol with hydrogen peroxide, Crit. Rev. Environ. Sci. Technol. 41 (2011) 125-167.

[26] T. Yamashita, P. Hayes, Effect of curve fitting parameters on quantitative analysis of $\mathrm{Fe}_{0.94} \mathrm{O}$ and $\mathrm{Fe}_{2} \mathrm{O}_{3}$ using XPSJ. Electron Spectrosc. Relat. Phenom. 152 (2006) 6-11.

[27] S. Wang, Comparative study of Fenton and Fenton-like reaction kinetics in decolourisation of wastewater, Dyes Pigm. 76 (2008) 714-720.

[28] M. T. Kreutzer, F. Kapteijn, J. A. Moulijn, J. J. Heiszwolf, Multiphase monolith reactors: Chemical reaction engineering of segmented flow in microchannels, Chem. Eng. Sci. 60 (2005) $5895-5916$. 
[29] J. Carbajo, A. Quintanilla, J. A. Casas, Assessment of carbon monoxide formation in Fenton process: the critical role of pollutant nature and operating conditions, Appl. Catal. B Environ. Submitted.

[30] K. M. Valkaj, A. Katovic, S. Zrnčević. Investigation of the catalytic wet peroxide oxidation of phenol over different types of Cu/ZSM-5 catalyst, J. Hazard. Mat. 144 (2007) 663-667.

[31] V. Subbaramaiah, V.Ch. Srivastava, I. D. Mall, Optimization of Reaction Parameters and Kinetic Modeling of Catalytic Wet Peroxidation of Picoline by Cu/SBA-15, Ind. Eng. Chem. Res. 52 (2013) 9021-9029

[32] J.L. Diaz de Tuesta, A. Quintanilla, J.A. Casas, J.J. Rodriguez, Kinetic modeling of wet peroxide oxidation with a carbon black catalyst, Appl. Catal. B Environ. 209 (2017) 701-710.

[33] C.R. Wilke, P. Chang, Correlation of diffusion coefficients in dilute solutions, AIChE J. 1 (1995) 264-279. 
Table 1. Characterization of $3 \mathrm{D}$ printed $\mathrm{Fe} / \mathrm{SiC}$ monoliths as a function of the SPS temperature: apparent density $\left(\rho_{\mathrm{p}}\right)$, total porosity $\left(\varepsilon_{\mathrm{t}}\right)$, specific surface area $\left(\mathrm{S}_{\mathrm{BET}}\right)$, the

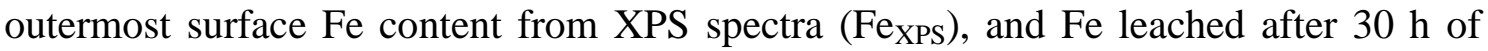
stream determined by TXFR ( $\mathrm{Fe}_{\text {leached }}$ ). The reference monoliths (REFERENCE) have also been included for comparison purposes.

\begin{tabular}{ccccccc}
\hline Monoliths & $\begin{array}{c}\text { SPS temperature } \\
\left({ }^{\circ} \mathrm{C}\right)\end{array}$ & $\begin{array}{c}\rho_{\mathrm{p}} \\
\left(\mathrm{g} \cdot \mathrm{cm}^{-3}\right)\end{array}$ & $\begin{array}{c}\varepsilon_{\mathrm{t}} \\
(\mathrm{vol} . \%)\end{array}$ & $\begin{array}{c}\mathrm{S}_{\mathrm{BET}} \\
\left(\mathrm{m}^{2} \cdot \mathrm{g}^{-1}\right)\end{array}$ & $\begin{array}{c}\mathrm{Fe}_{\mathrm{XPS}} \\
(\mathrm{wt} . \%)\end{array}$ & $\begin{array}{c}\mathrm{Fe}_{\text {leached 30h }} \\
(\mathrm{wt} . \%)\end{array}$ \\
\hline REFERENCE & --- & 1.13 & 70.0 & 30.9 & 0.33 & 18.5 \\
SPS-1000 & 1000 & 1.44 & 68.9 & 29.4 & 0.23 & 11.0 \\
SPS-1200 & 1200 & 1.51 & 67.3 & 23.5 & 0.22 & 10.1 \\
SPS-1500 & 1500 & 1.72 & 65.6 & 22.0 & 0.20 & 5.2 \\
& & & & & & \\
\hline
\end{tabular}



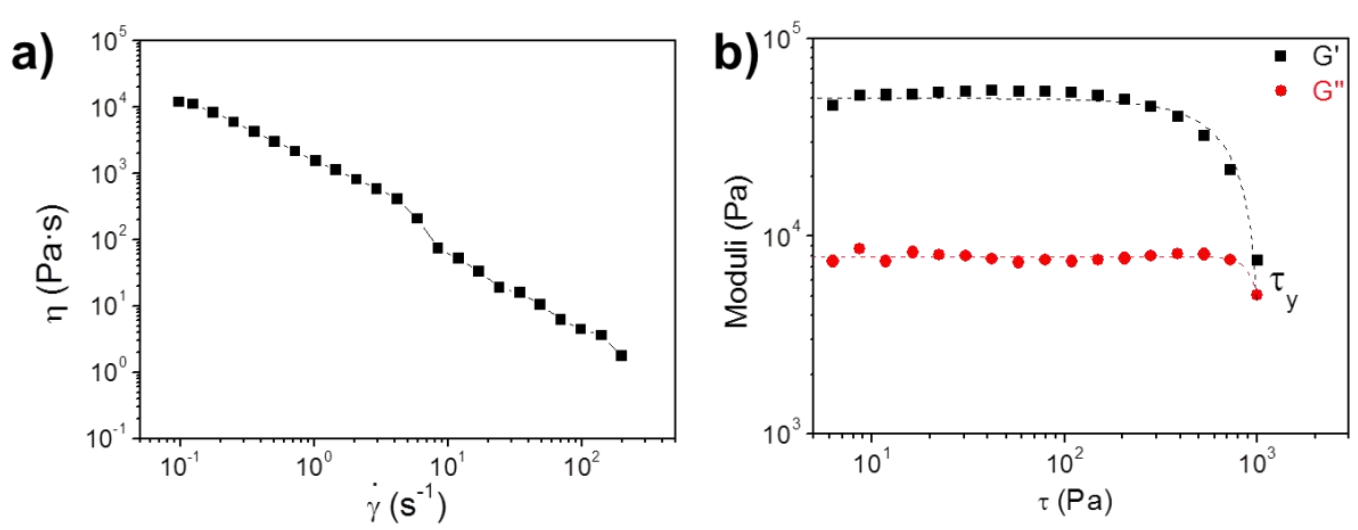

c)
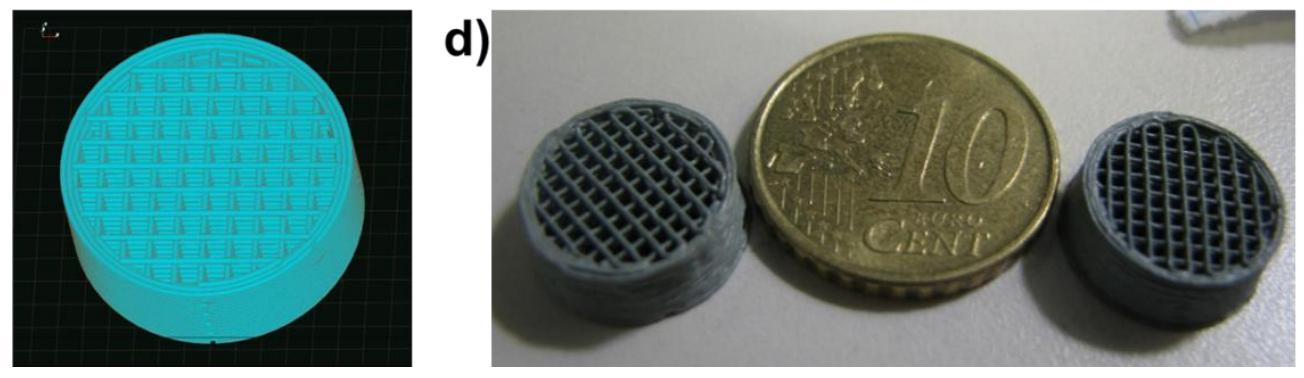

Figure 1. Rheological behaviour of $\mathrm{Fe} / \mathrm{SiC}$-based inks and 3D printed scaffolds. a)

Apparent viscosity $(\eta)$ versus shear rate $(\gamma)$ and b) storage $\left(G^{\prime}\right)$ and loss $\left(G^{\prime \prime}\right)$ moduli versus shear stress $(\tau)$ for the SiC-based ink. c) CAD patterned structure and d) examples of 3D cylindrical Fe/SiC scaffolds after the burning-out process (reference material, REFERENCE) comparing their sizes with a coin of 10 euro cents. 
a)

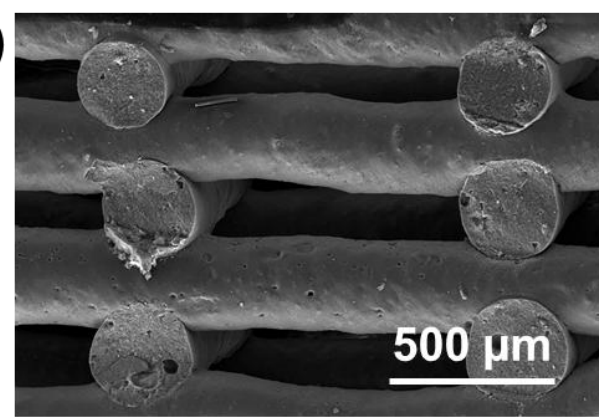

c)

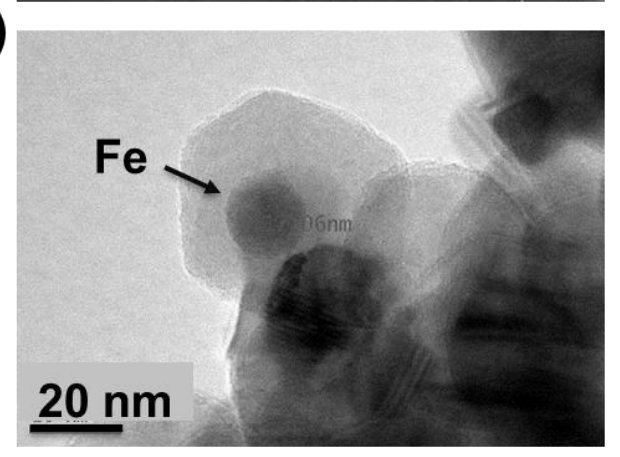

b)

d)
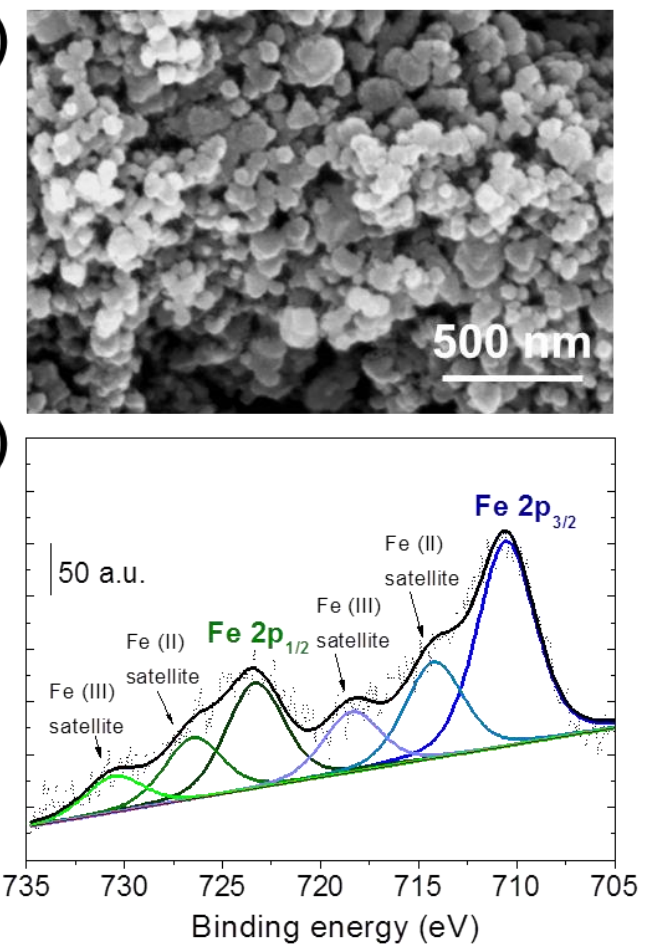

Figure 2. a) FESEM micrographs showing a cross section of a scaffold showing the woodpile arrangement and b) typical microstructure of nanosized SiC grains inside the strust and c) TEM image of SPS-1200 showing an embedded Fe particle, and d) XPS spectrum and deconvolution of Fe $2 p$ peaks of the reference sample. 
a)
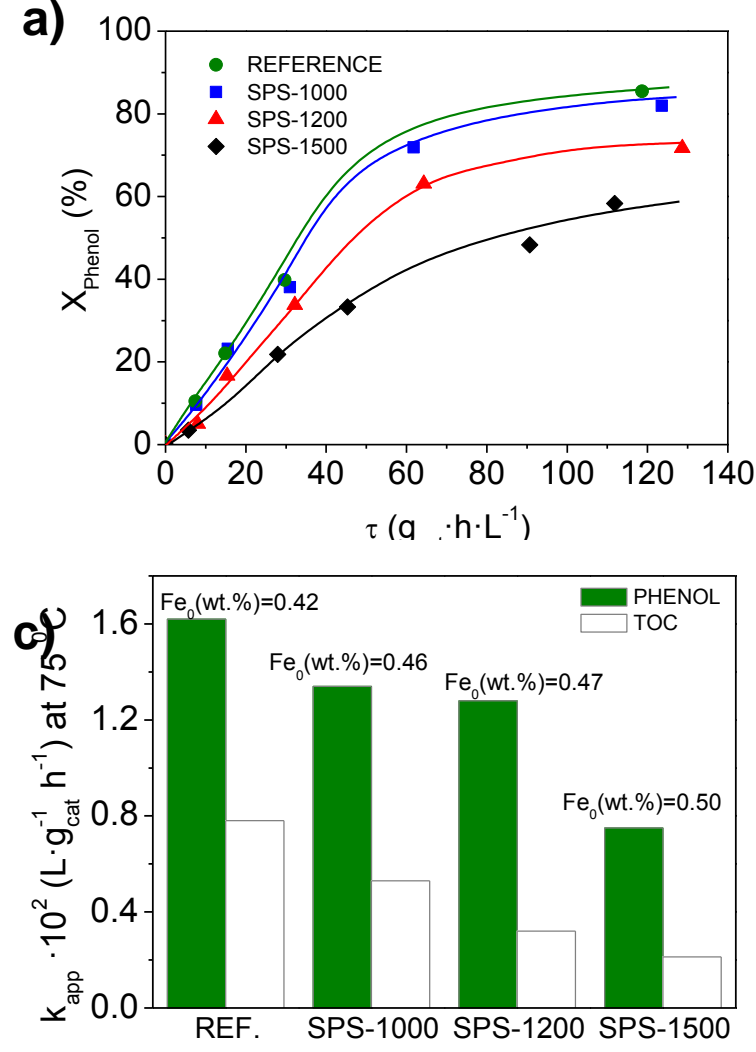

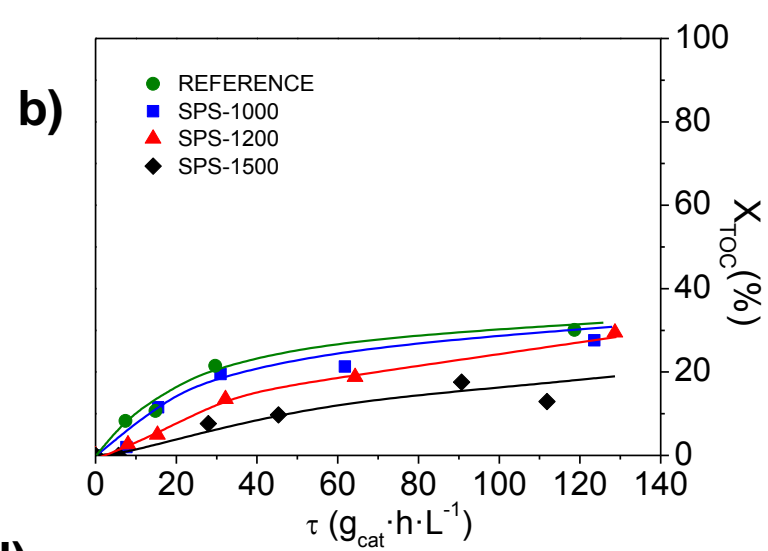

d)

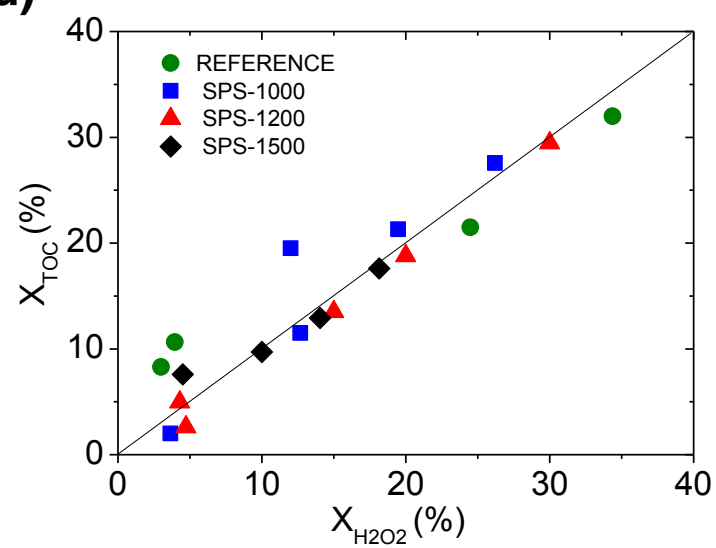

Figure 3. Conversions (X) profiles of a) phenol and b) TOC, c) apparent kinetic constants $\left(k_{a p p}\right)$ of phenol disappearance and TOC removal as a function of the SPS temperature, d) efficiency in the $\mathrm{H}_{2} \mathrm{O}_{2}$-consumption in presence of 3D-printed $\mathrm{Fe} / \mathrm{SiC}$ monoliths. 

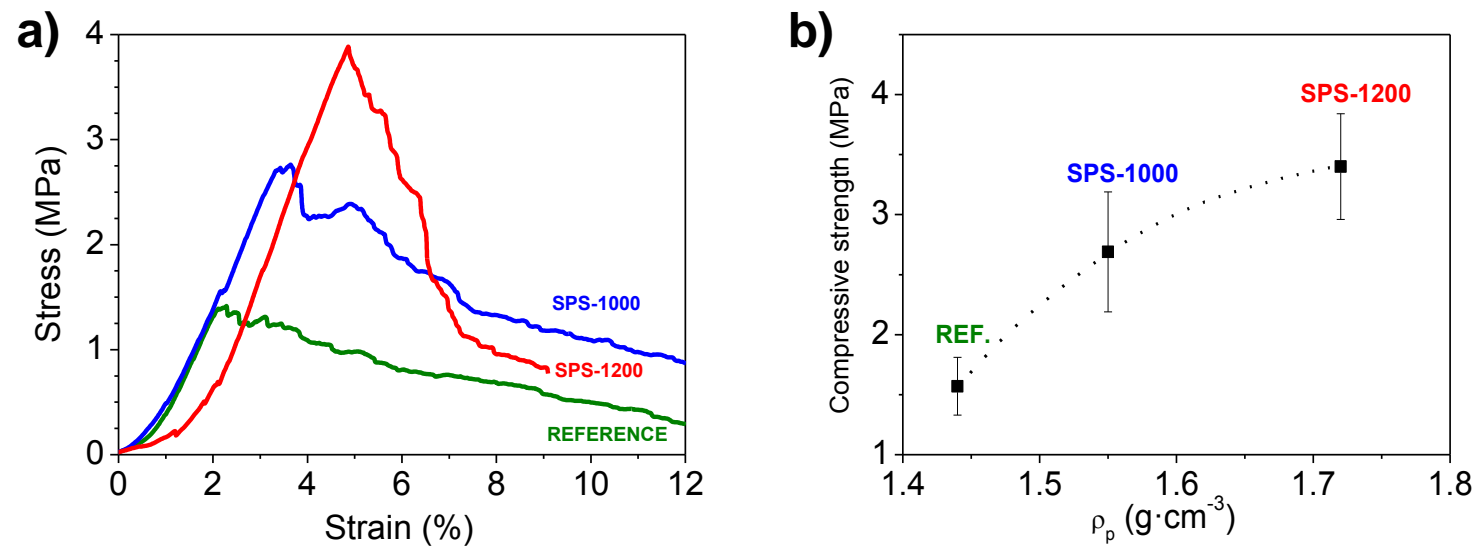

Figure 4. Mechanical resistance of the monoliths. a) Representative stress-strain curves for the REFERENCE, SPS-1000 and SPS-1200 scaffolds, and b) compressive strength $(\sigma)$ versus the apparent density $\left(\rho_{p}\right)$. 


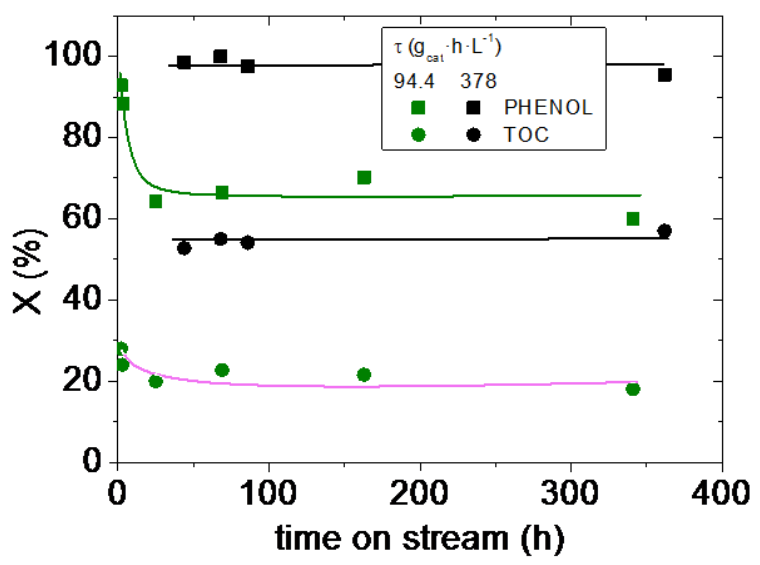

Figure 5. Long-term run of SPS-1200 $\mathrm{Fe} / \mathrm{SiC}$ monolith tested at $75{ }^{\circ} \mathrm{C}$ and different space times. 

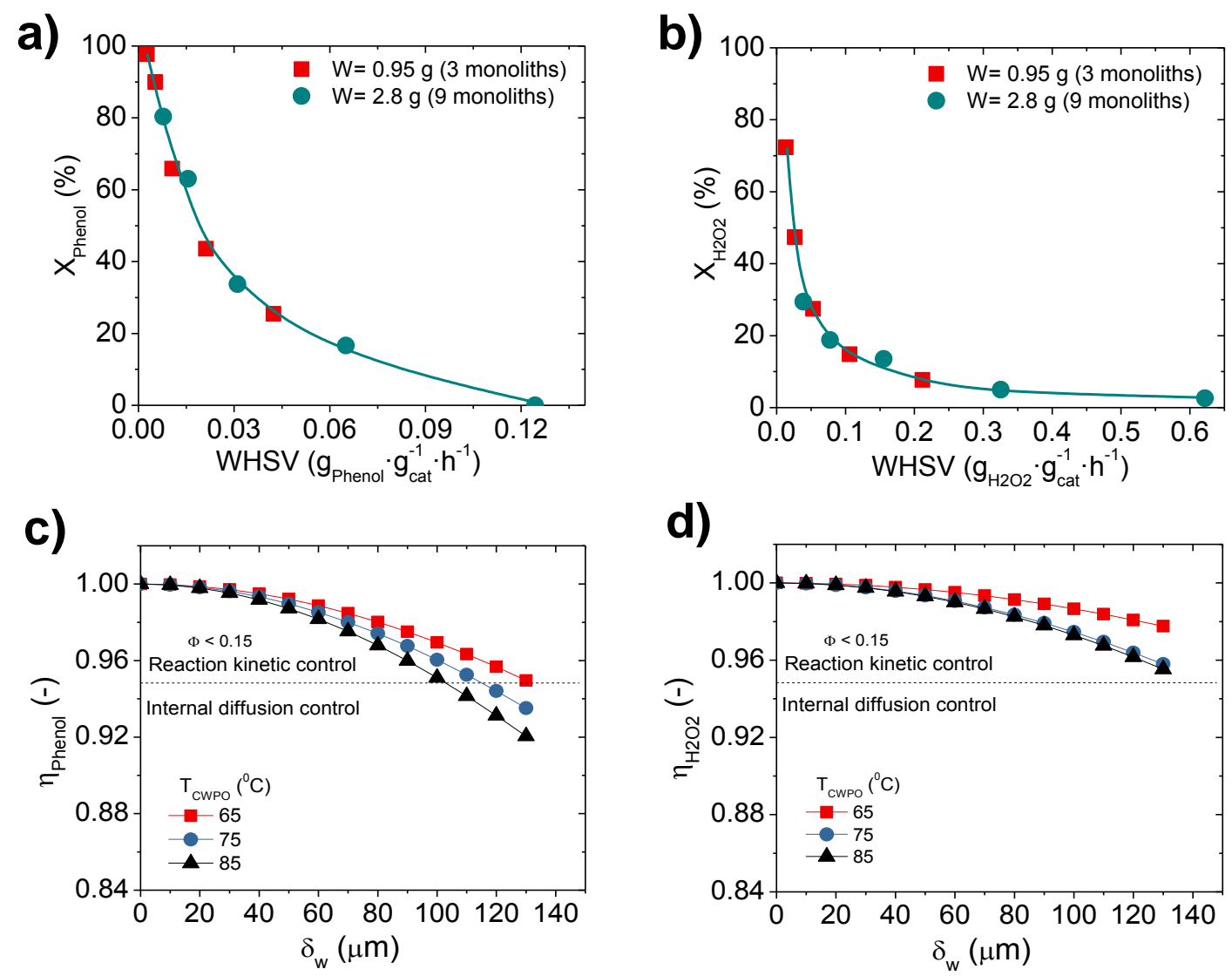

Figure 6. a) Phenol conversion $\left(\mathrm{X}_{\text {phenol }}\right)$ vs. WHSV, b) $\mathrm{H}_{2} \mathrm{O}_{2}$ conversion $\left(\mathrm{X}_{\mathrm{H} 2 \mathrm{O} 2}\right)$ vs. WHSV, c) internal mass transfer effectiveness factor for phenol ( $\left.\eta_{\text {phenol }}\right)$ and d) $\mathrm{H}_{2} \mathrm{O}_{2}$ $\left(\eta_{\mathrm{H} 2 \mathrm{O} 2}\right)$ as a function of the channel wall thickness of the SPS-1200 Fe/SiC monoliths at different CWPO temperatures. 
a)

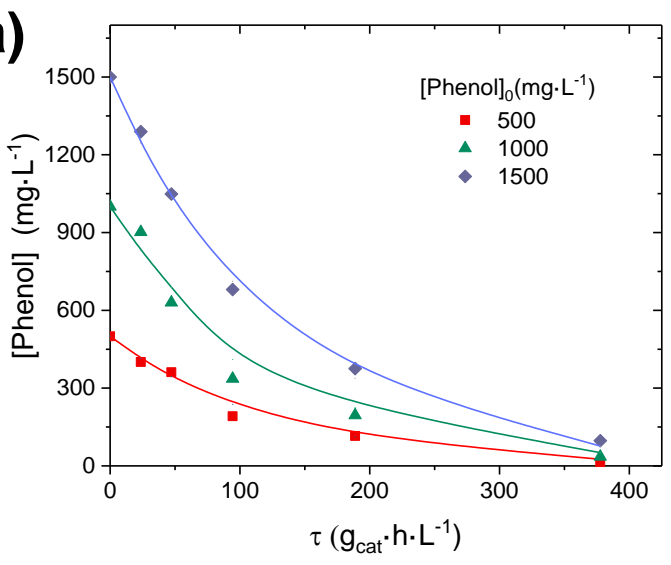

b)

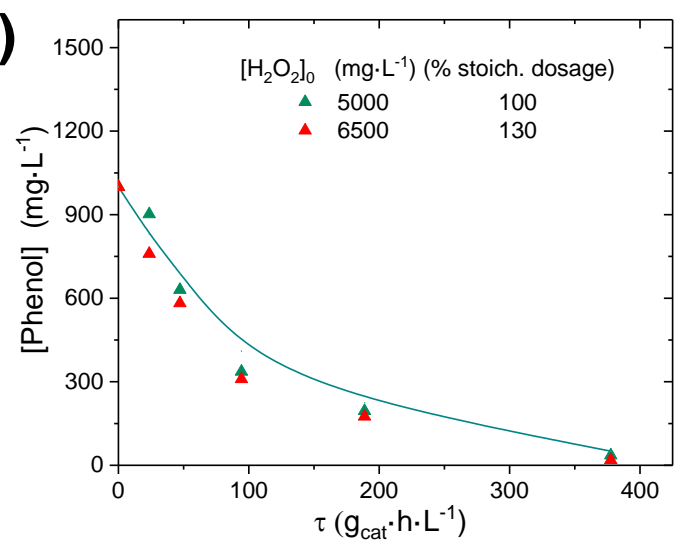

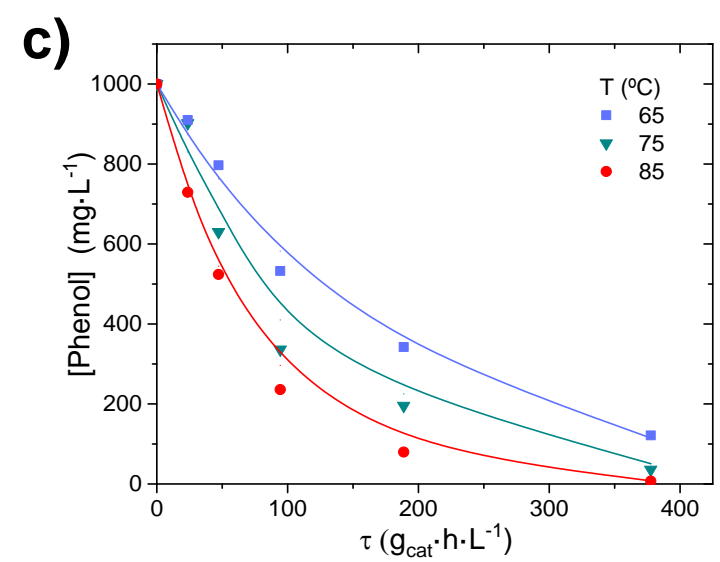

Figure 7. Experimental (symbols) and predicted (curves) time-course of phenol concentration under different operating conditions. 
a)

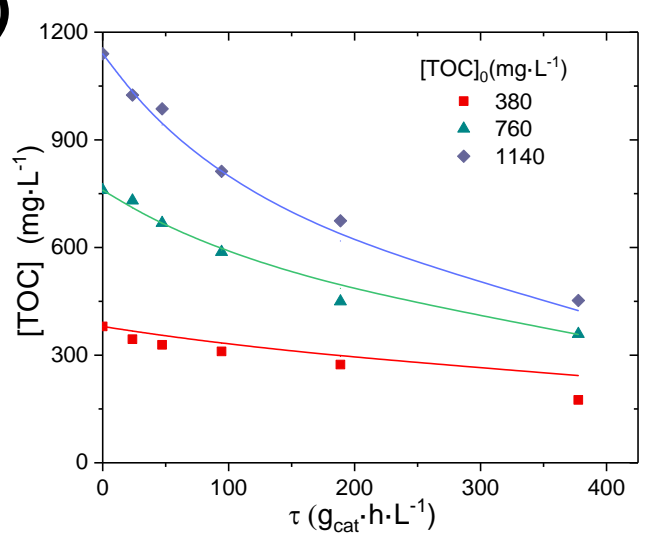

b)

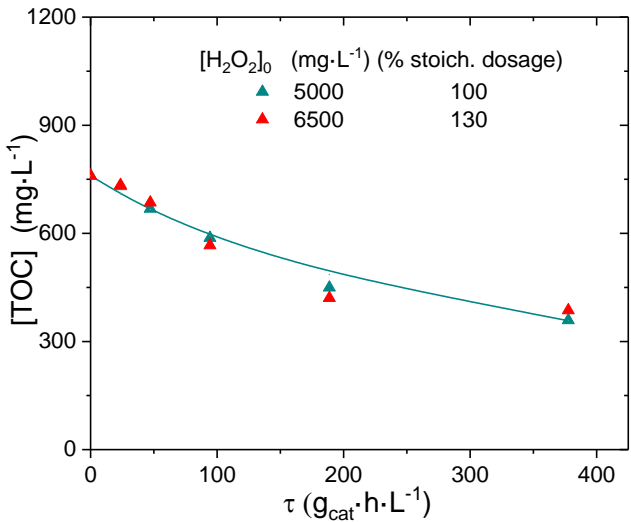

c)

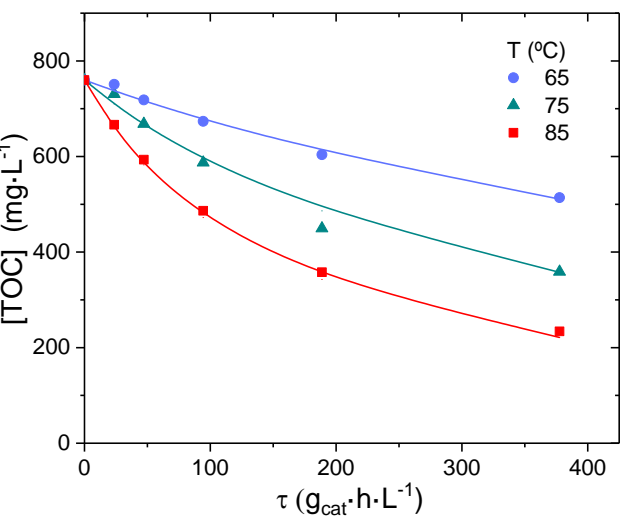

Figure 8. Experimental (symbols) and predicted (curves) time-course of TOC concentration under different operating conditions. 
a)

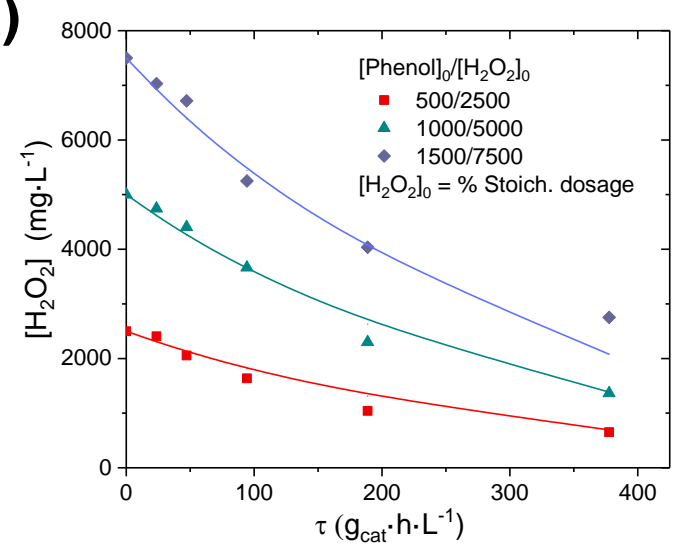

b)

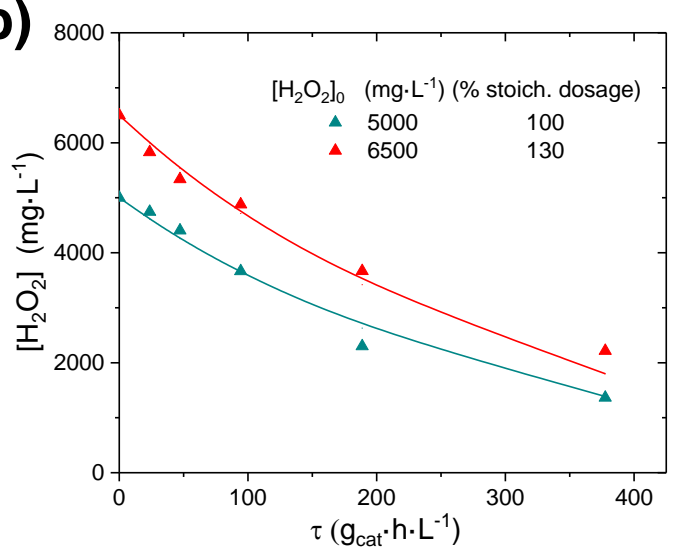

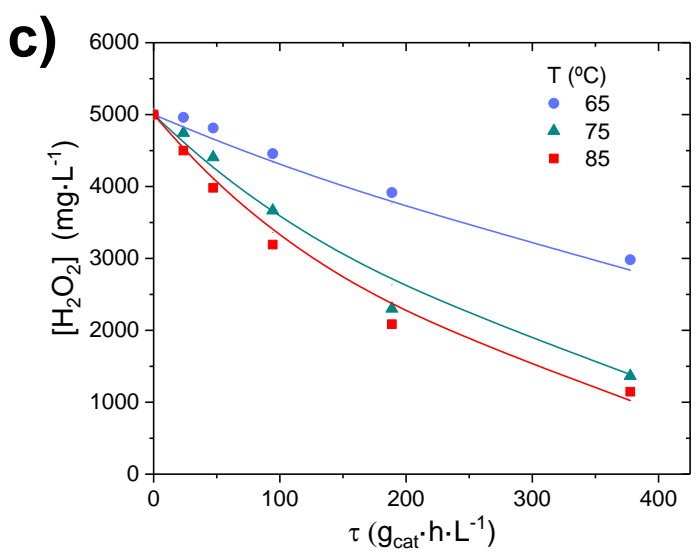

Figure 9. Experimental (symbols) and predicted (curves) time-course of TOC concentration under different operating conditions. 
3D-Printed Fe-Doped Silicon Carbide Monolithic Catalysts for Wet Peroxide Oxidation Processes

A. Quintanilla*\$, J. A. Casas ${ }^{\S}$, P. Miranzo ${ }^{\ddagger}$, M. I. Osendi ${ }^{\ddagger}$, M. Belmonte ${ }^{*}$

${ }^{\S}$ Sección de Ingeniería Química, Universidad Autonoma de Madrid, 28049 Madrid, Spain

${ }^{\ddagger}$ Institute of Ceramics and Glass (ICV-CSIC), 28049 Madrid, Spain

* Corresponding authors. Tel/Fax: +34 914973454/+34 914973516. E-mail address: asun.quintanilla@uam.es, $\underline{\text { mbelmonte@icv.csic.es }}$

\section{Graphical Abstract}
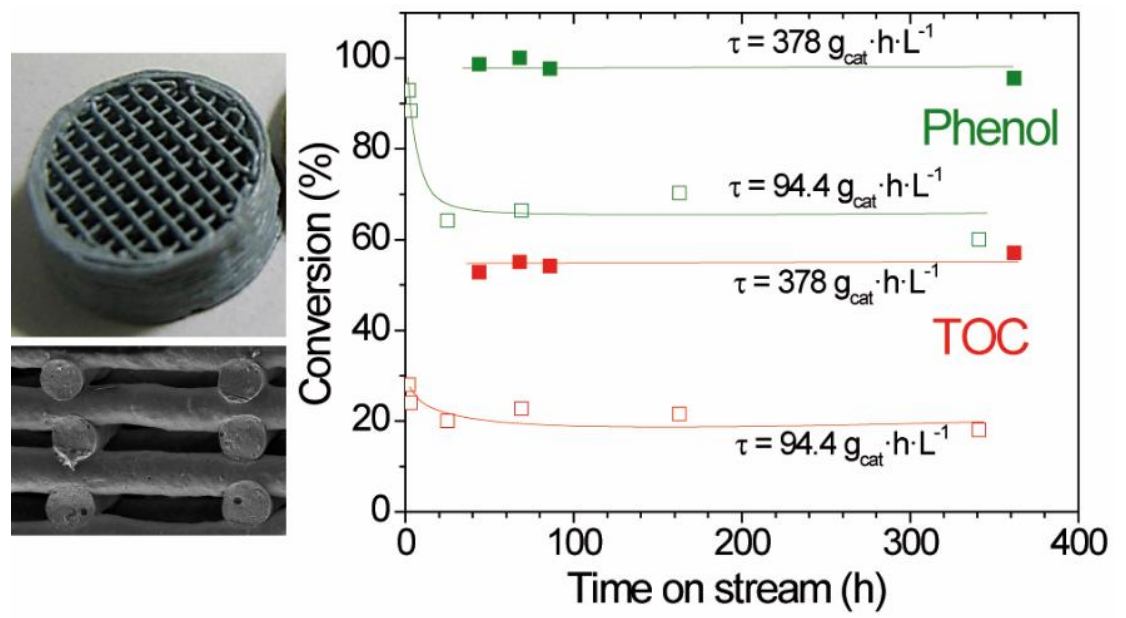


\section{Highlights}

- Robust 3D printed $\mathrm{Fe} / \mathrm{SiC}$ monoliths were fabricated by direct ink writing.

- $\mathrm{Fe} / \mathrm{SiC}$ monoliths were successfully evaluated for CWPO process.

- Heat treatments of monoliths tuned their catalytic and mechanical properties

- Good catalytic activity, long-term stability and good mechanical strength attained.

- The kinetic model based on a set of potential equations adequately describes the CWPO of phenol. 
Supplementary Material
Click here to download Supplementary Material: Supporting information_9FEBR.docx

Supplementary Material
Click here to download Supplementary Material: Supporting information_9FEBR.docx

Click here to down

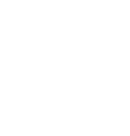

$\sqrt{3}$

$\sqrt{3}$

$\sqrt{2}$

(1)

. (1) (1) . . . . . . . . . . . . . . . 